\title{
ESTÉTICA, SUBJECTIVAÇÃO E PÓS-HUMANO: DO ADMIRÁVEL AO SUBLIME. UM PASSO ATRÁS?
}

\section{Maria Manuel Baptista}

\section{Resumo}

Na senda dos processos de dessubjectivação levados a cabo por Marx, Freud e Nietzsche, o que defendemos nesta reflexão, seguindo as pistas deixadas em aberto por Luc Ferry (1991), é que a arte e os artistas contemporâneos têm, por múltiplas vias e sobretudo articulando e confrontando corpo e máquina, levado a cabo uma ressignificação da arte e da própria subjectividade. Este estudo pretende traçar alguns dos desenvolvimentos que a este propósito assistiu o século XX e já XXI através de um percurso que articula estética e subjectividade. Começando por colocar a arte entre 'o coração e a razão', faremos uma espécie de pré-história da estética ou a designada querela dos 'cogita', sublinhando em seguida a importância dos momentos Kantiano, Hegeliano e Nietzscheano na discussão desta temática. Em seguida abordaremos as questões relativas ao corpo maquínico, procurando utilizar as principais intuições estéticas kantianas para pensar as aporias e possibilidades do pós-humano. Concluiremos, assim, da necessidade de dar 'um passo atrás em direcção ao Homem ou ao Ciborg-Homem', que possa permitir ultrapassar o paradigma estético hegeliano e regresse às modalidades kantianas do juízo estético para pensar a arte contemporânea e os seus actuais desafios.

\section{Palavras-chave:}

Arte Contemporânea, Estética, Hegel, Kant, Subjectividade, Pós-Humano, Cyborg.

Adoptando o ponto de vista de Luc Ferry (1991, p.14), segundo o qual “(...) a estética é, por excelência, o campo em que as questões levantadas pela subjetivação do mundo característica dos Tempos modernos podem ser observadas, por assim dizer, no estado quimicamente puro", o presente texto parte da reflexão estética para encontrar os modos de subjectivação que os processos artísticos

\section{Abstract}

In the wake of desubjectivation processes carried out by Marx, Freud and Nietzsche, what we stand for in this reflection, following the tracks left open by Luc Ferry (1991), it is that art and contemporary artists have, by multiple pathways and particularly articulating and confronting body and machine, carried out a reframing of art and of human subjectivity. This study aims to trace some of the developments of this issue in the twentieth century and now XXIst, via a route that links aesthetics and subjectivity. Starting to put the art between the 'hearts and minds', we will make a kind of prehistory of aesthetics or the so called 'cogito's debate', underlining then the importance of Kantian, Hegelian and Nietzschean moments in the discussion of this issue. Then we discuss the mechanic body, trying to use the main Kantian aesthetic intuitions to think the aporias and possibilities of the post-human. We conclude, therefore, of the need to 'step back towards the man or the Ciborg-Man' which would permit surpass the Hegelian aesthetic paradigm and return to Kantian modes of aesthetic judgment to think the contemporary art and its current challenges.

Keywords:

Contemporary Art, Aesthetics, Hegel, Kant, Subjectivity, Post-Human, Cyborg.

contemporâneos desenham através da articulação e confrontação do corpo e da máquina.

Com efeito coube à arte contemporânea experimentar todas as modalidades de dessubjectivação, inaugurando pela via estética o que a pós-modernidade cultural e filosófica conhecerá como descentração e implosão do sujeito 
uno da modernidade. Usando o corpo próprio, por vezes forçando os seus limites, ao mesmo tempo em que procurou a dessubjectivação, o artista foise desdobrando em múltiplas experimentações de ressignificação e expansão da subjectividade, com ele arrastando para o domínio específico da arte as questões que eram, tradicionalmente, colocadas no campo da filosofia. Assim, a reflexão sobre o belo foi substituída pela questão da subjectividade, o corpo passou a ser interrogado, articulado e desafiado pela máquina, o 'admirável' mundo pós-humano reforça antigas questões ligadas não só à legitimidade, especificidade e autonomia do campo de produção artística, como também retoma interrogações que se referem à qualidade e relevância dos processos de conhecimento, que a partir deles se estabelecem e, por fim, exige articulações cada vez mais profundas entre ética e estética.

O que defenderemos nesta reflexão, seguindo as pistas deixadas em aberto por Luc Ferry (idem) é que, após as desconstruções da subjectividade levadas a cabo por Marx, Freud e Nietzsche será necessário um passo atrás em busca de outra linha teórica e estética que conduza a uma possível ressignificação da arte, como modo de produção de conhecimento, ou antes de conhecimentos e subjectividades, onde corpo e máquina, real e virtual, ética e estética possam ser pensados, precisamente a partir de novos processos de subjectivação próprios da pós-modernidade.

\section{Estética e subjectividade}

Seguindo de perto a sistematização que nos propõe Ferry, destacaremos com ele cinco grandes momentos decisivos na evolução da questão do sujeito:

a) Entre o coração e a razão: a pré-história da estética ou a querela dos "cogito"

Desde o século XVII que na estética se digladiam duas concepções de arte (duas visões diferentes da subjectividade e ambas no domínio de uma concepção individualista): uma que defende que a arte deve dizer a realidade (tal como a ciência), e deve estar ao serviço da verdade e outra que, pelo contrário, considera que a arte deve expressar o sentimento, naquilo que ele tem de indizível.

A primeira provem sobretudo de uma concepção cartesiana de cogito, cuja essência é ser racional e a outra radica numa concepção eminentemente pascaliana e sensualista, que situa o essencial da arte no coração.

Mas, apesar das oposições, partem ambas de uma concepção monadológica do sujeito: a comunicação entre estas mónadas só se pode fazer por meio de uma mediação (em Leibniz é Deus, mas pode também ser a Natureza ou uma qualquer outra entidade). Assim, neste modelo, a comunicação, é assegurada por meio de um Deus, do racionalismo de Leibniz ao empirismo de Berkley e Hume.

É contra este modelo que se constitui a Aesthetica de Baumgarten, que institui um recuo do ponto de vista divino sobre o humano, procurando a autonomia da sensibilidade. No entanto, porque ainda se encontra demasiado fechada no racionalismo de Leibniz, esta primeira tentativa não consegue ultrapassar certo platonismo, continuando a reproduzir certa hierarquia, que desvaloriza o belo em detrimento do verdadeiro e do bem.

\section{b) O Momento Kantiano}

Ainda na linha de Ferry, Kant será o primeiro a conferir uma verdadeira autonomia ao domínio da arte, afastando-se, assim, definitivamente do quadro do classicismo. Ao inverter o platonismo (que postulava o primado do inteligível sobre o sensível), Kant altera também a concepção de subjectividade. De facto, ao valorizar o sensível, valoriza o conhecimento finito, logo, a natureza humana, que assim se distingue da natureza divina.

Defende Ferry (1991, p.45) que

a afirmação da autonomia do sensível não significa nada menos, neste contexto, que a separação radical, talvez definitiva, do humano e do divino. (...) É um golpe fatal para o antigo estatuto do divino, um ato de orgulho do qual não é exagerado dizer que é, na ordem do espírito, comparável àquele outro crime de lesa divindade que é a Revolução na ordem do político.

O aparecimento de outra figura da subjectividade, o juízo reflexivo, no contexto da estética coloca igualmente o problema do acordo dos gostos, ou do senso comum (questão que não se resolverá em Kant de forma monadológica, quer dizer, teológica). Recorrendo à noção de intersubjectividade, Kant faz-nos entrar no universo moderno, no mundo da laicidade, como veremos adiante.

Do ponto de vista do criador, há também modificações, pois o criador deixa de ser aquele 
que apresenta ou descobre verdades, para ser um verdadeiro criador: "O génio faz a sua aparição e a imaginação tende tornar-se a 'rainha das faculdades', rivalizando com o divino na produção de novas obras radicalmente inéditas" (idem).

\section{c) O Momento Hegeliano}

A estética de Hegel, grandiosa e com momentos brilhantes, esforçou-se por reinterpretar a teoria do génio, procurando defender o classicismo das brechas que Kant aí abrira: assim, procurou que a reflexão, essência da subjectividade finita, fosse apenas um momento a ser ultrapassado, na proposição especulativa.

Deste modo, em Hegel, a sensibilidade perde autonomia, e a estética transforma-se de novo na expressão de uma ideia no campo da sensibilidade. A diferença com o classicismo dos séculos XVII e XVIII é que ela se transforma agora numa história da arte, sendo a arte sempre um fenómeno do passado: " $A$ reflexão e o génio devem, portanto, ceder o passo ao sujeito absoluto, ao qual só a filosofia pode pretender dar-nos acesso" (ibidem, p.46).

\section{d) O Momento Nietzscheano}

Embora possa parecer paradoxal, a estética de Nietzsche aproxima-se mais de Kant do que de Hegel, pelo papel de autonomização do ponto de vista humano sobre o divino. Com Nietzsche, é Deus quem morre, para dar lugar a um sujeito 'estilhaçado', não transparente a si próprio, porque aberto à alteridade do inconsciente.

Com o perspectivismo de Nietzsche ('não há factos mas apenas interpretações'), surge um novo individualismo, que conduz tanto ao subjectivismo total como ao relativismo absoluto. Desaparece a noção de verdade enquanto adequação e identidade, bem como qualquer possibilidade de monadologia, que harmonize as diversas visões num único sistema do mundo. Tal como o afirma Heidegger, o nietszcheanismo é uma monadologia sem Deus. O mundo é pura multiplicidade, diferença absoluta que só a arte pode expressar.

Para Ferry, é o duplo movimento da estética nietszcheana (hiperrelativismo e hiperrealismo, este que acaba por estar muito perto das concepções de subjectividade de raiz platónica), que está subjacente às expressões da arte contemporânea ligadas ao Vanguardismo (o que de resto veremos em momento posterior desta reflexão).

Com efeito, Nietzsche, enquanto filósofo do mundo da hiperindividualidade vai ao encontro da ideologia revolucionária mais extrema, da 'subjectividade', dos valores da originalidade e inovação, da negação da tradição. Trata-se, paradoxalmente, de retornar aos valores neocartesianos da tábua rasa, num momento em que se quer destruir todo o passado.

$\mathrm{Na}$ sua vertente hiperrealista, o Vanguardismo parece chegar, ao opôr-se a todo o barroco, a um hiperclassicismo (veja-se o fascínio dos cubistas e surrealistas, entre outros, pela geometria), que busca outras dimensões espaciais para a expressão plástica, que sejam mais reais que as do mero espaço euclidiano.

Seguindo ainda a reflexão de Ferry, hoje, na política como na arte, não há mais vanguardas. O que hoje temos são post-vanguardas: “Estamos a entrar decididos, senão felizes, na era do pós-vanguarda, ou como dizem os arquitectos do "pós-moderno": a inovação deixou de ser a regra de ouro e o retorno às tradições perdidas, o "revivalismo", adquire uma certa legitimidade" (FERRY, 1991, p.49).

O real não é mais definido como caos, desarmonia ou dissonância, e a arte mais recente (da música à literatura, passando pela pintura), parte de uma nova figura do sujeito e da sua relação ao mundo, um mundo que hoje se encontra cada vez mais virtualizado e em retirada. Em conclusão, “(...) no termo de uma tal história da subjetividade é de novo para o estatuto da cultura numa sociedade democrática, numa sociedade de indivíduos emancipados do mundo da tradição, que nós seremos inevitavelmente reconduzidos" (idem).

\section{0 admirável corpo maquínico pós-humano}

Na sua muito completa reflexão sobre "Culturas e Artes do Pós-Humano - da cultura das mídias à cibercultura" (2008), Lúcia Santaella coloca exactamente a questão deixada em aberto por Luc Ferry, interrogando-se sobre o que poderá vir a ser a Arte depois da Arte (p. 315). Recordando o modo como Hegel sublinha a incapacidade da arte para satisfazer a exigência de Absoluto por parte do Espírito, refere que ela só se pode entender como "coisa do passado" (ibidem). Por seu turno, sublinha que esta morte não foi apenas levada a cabo pela filosofia e pelos filósofos, mas também 
as próprias vanguardas estéticas anunciaram um 'pretenso suicídio da arte' (p.316). Porém, tal como uma "fénix renascida" (p.317)

(...) um novo paradigma tecnológico e maquínico para as artes [surge](...), tendo o seu início na fotografia, prolongou-se no cinema e na holografia, continuou na revolução electrónica, que trouxe consigo o vídeo, para culminar nas imagens computacionais e nas redes comunicacionais da actual revolução digital. (ibidem, p.318)

Em suma, mais do que uma substituição de paradigmas, o que parece estar a verificar-se no momento é uma sobreposição de todas as artes, tendência que não cessa de se aprofundar e que contraria a percepção de um fim para a arte. Partilhando da leitura de Vattimo, Santaella defende que "a morte da arte constitui, portanto, a época do fim da metafísica como Hegel a profetizou, como Nietzsche a viveu e Heidegger a registou" (p.321). Ora o que morreu foi o conceito renascentista de autor, que continha certa concepção de subjectividade a partir da qual a nossa relação com as imagens se formou. A pós-modernidade virá, de acordo com a autora, colocar em causa este conceito de autor, promovendo em simultâneo “(...) o questionamento da concepção de tempo e de história como progressão linear, teleológica que norteou o projecto da modernidade" (p. 323).

\section{E prossegue:}

Do bojo desse questionamento nasciam práticas e desejos proliferantes, justapostos e disjuntos direccionados para a multiplicidade em detrimento da unidade, da diferença em lugar da identidade, para o movimento dos fluxos e dos arranjos móveis em detrimento dos sistemas. Foi nas artes que essa efervescência se fez mais sentir (...). (ibidem, p. 323)

Reforçando este movimento, encontramos ainda a teoria do não-objecto que

(...) antecipou a tendência para a imaterialidade do objecto artístico, manifesta tanto na arte conceitual quanto nas artes electrónicas actuais feitas de luzes que desvanecem no tempo e de fluxos e refluxos instáveis de energia e informação. (ibidem, p.324)

O resultado de toda esta situação leva a autora a uma enorme perplexidade e incerteza relativamente ao que hoje pode ser considerado arte. De qualquer modo, chama a atenção para o facto de que,

quando novos suportes tecnológicos surgem, são os artistas que sempre tomam a dianteira na exploração das possibilidades que se abrem para a criação. É em razão disso que um filão importante das artes actuais está localizado nas produções que fazem uso das tecnologias digitais, das memórias electrónicas, das hibridizações dos ecossistemas com os tecnossistemas. (ibidem, p.326)

A partir daqui, a autora passa a referir-se à bioarte ou arte biológica e mais especificamente à biotelemática (onde os processos biológicos se encontram associados às telecomunicações computorizadas) e à arte transgénica (que utiliza a engenharia genética para criar novas formas de vida).

É claro que aqui estamos já no seio do cruzamento ente arte, ética, técnica e filosofia. Disto mesmo se apercebe a autora ao afirmar: "quando o próprio design da vida está em jogo e posto nas mãos dos humanos, a sensibilidade à flor da pele do artista não pode deixar de atender a esse chamamento" (p.328).

Estaremos ainda no domínio da arte ou da estética? $E$ de que arte ou de que estética? Santaella lança mão de Pierce, que, de algum modo, legitima “(...) a obsessão do artista, porque respira o oxigénio de uma destinação inalienável para o admirável que, segundo Pierce (...) consiste no empenho ético direccionado para o ideal estético de levar a razão estética a crescer no mundo" (p.329).

Ora é aqui que começam as nossas dificuldades: de que "razão estética", que deverá crescer no mundo, estamos nós a falar?

A autora responde, recorrendo de novo a Pierce, que teria desenvolvido uma teoria estética absolutamente inovadora: "por estética ele não entendia uma ciência do belo, mas uma ciência que tem por tarefa indagar sobre estados de coisas que são admiráveis por si sem qualquer razão ulterior" (p.329).

Ora, muito antes de Pierce, tinha Kant constituído todo um campo de autonomização do juízo estético e, para além disso, retirado a estética da mera discussão em torno do Belo para a catapultar para além disso, para o Sublime.

A grande diferença entre Kant e Pierce é que o fim último da ética não é a estética, pelo que não caberia ao Homem/Sujeito/Artista tornar-se Deus para (re)criar a humanidade e o mundo. Quer dizer, enquanto na reflexão de Pierce/Santaella encontramos a aspiração a um artista homo-divino-ex-maquina apostado no ideal do crescimento da razão criativa no seio da vida, "introjectando a semente do admirável" no campo da acção experimental da ciência, "transmitindo ao 
cientista o apelo do admirável" (p.333), em Kant, como veremos, a arte é reconduzida à sua condição humana, demasiado humana.

\section{Do juízo de gosto à estética do sublime - Kant}

A obra de Kant desde cedo recebeu uma atenção proporcional à revolução que pretendeu introduzir no modo como se compreendia (e em especial na ciência) o modo de produção de conhecimentos válidos sobre o mundo. Se na sua "Crítica da Razão Teórica", Kant procede a uma Revolução Coperniciana, ao chamar a atenção para o papel determinante do plano transcendental do sujeito na produção de juízos sintéticos a priori (verdadeira garantia de validade do conhecimento científico), deixando o númeno - o que poderia ser 'o mundo' 'o em si', 'a verdade' - na esfera do incontornavelmente incognoscível para o sujeito, desloca a ontologia para uma espécie de antropologia que, longe de limitar o campo e acção humana Ihe amplia e legitima as suas possibilidades.

Do mesmo modo, na "Crítica da Razão Prática" a possibilidade de produção de um juízo moral encontra também no sujeito a dimensão formal do dever como garantia de uma lei moral, que se impõe à consciência e funda, pela via prática, a necessidade absoluta do Infinito, logo de Deus. No entanto, essa legitimação última em Deus, pela via da acção moral prática não desloca de modo nenhum o centro da exigência ética que continua a residir na acção conforme a lei moral, que o sujeito moral reconhece presente em si como uma tensão para a perfeição (no caso a santidade).

Seguindo esta muito original onto-antropologia, que funda o mundo como um mundo humano, verificamos que Kant produz uma obra dedicada à estética que, embora não tendo sido aquela que vinga na modernidade e depois na pós-modenidade (como Luc Ferry muito bem sublinha), vai na mesma linha das anteriores Críticas: com efeito na "Crítica da Faculdade de Julgar", dedicada à estética, Kant fará residir a possibilidade do juízo estético também no plano transcendental, quer dizer no plano do humano (e não do divino), ao mesmo tempo que prolonga a estética do domínio do Belo para atingir o Sublime (conceito que não pode deixar de nos lembrar da noção de 'Admirável' de que nos falava Pierce/Santaella). Como veremos, será através da estética que Kant poderá estabelecer a possibilidade da comunicação humana, ultrapassando as aporias em que ela se encontrava desde Leibniz, numa espécie de monadologia na qual o máximo que se esperava da comunicação sobre o belo entre os homens decorreria de forma indirecta e a necessitar de uma entidade divina para garantir um mundo não apenas feito de solilóquios.

\section{1 - A especificidade do juízo estético}

Philonenko, um dos maiores tradutores e estudiosos de Kant, chama a atenção para o facto de nem os juízos estéticos nem os teleológicos (ao contrário dos juízos matemáticos e físicos) poderem determinar ou construir a priori o seu objecto e, portanto, não poderem aspirar a uma universalidade objectiva. Assim, a sua universalidade é subjectiva.

Com efeito, a reflexão é o processo inverso ao esquematismo transcendental: enquanto a reflexão consiste num "(...) procedimento do espírito para procurar, no que é particular (imagem) a sua significação universal (o seu conceito) (...)" (PHILONENKO, 1974, p. 9), o esquematismo transcendental próprio da ciência consiste no “(...) procedimento da imaginação para procurar relativamente a um conceito (universal), a sua imagem (particular) (...)" (ibidem).

Mas o que é mais relevante nesta obra será assinalado por Philonenko nos seguintes termos: “(...) A Crítica da Faculdade de Julgar é uma tentativa de resolver o problema central da filosofia moderna: a intersubjectividade" (p.10).

Com efeito, a questão da intersubjectividade é particularmente revelada na questão Estética (como de resto também o sublinha CASSIRER, 1998), uma vez que aí a questão fundamental é saber-se como é que um sentimento particular a propósito de um objecto que eu designo de belo pode recolher o consenso universal ou tão só de outro ser humano. Em última análise, a questão que aqui se coloca é a de se saber como é possível a comunicação entre os homens, ultrapassando o "eu" para atingir o "outro". Daí a máxima da "Crítica da Faculdade de Julgar": 'pensar colocando-se no lugar do outro'.

$\mathrm{Na}$ verdade, se na primeira Crítica (da Razão Pura) a comunicação entre os homens decorre através do conhecimento (logo, de uma forma indirecta, apoiando-se no objecto ou conceito e não reencontrando aí directamente o homem), na segunda ("Crítica da Razão Prática"), é possível a comunicação do homem com o outro homem, 
enquanto ser racional. Trata-se de uma comunicação moral, de natureza indirecta, pois que é mediatizada pela lei moral, situação só ultrapassada na "Crítica da Faculdade de Julgar", na qual é possível uma comunicação directa do homem com o homem, sem passar pela mediação do conceito ou da lei.

De acordo com Philonenko, esta comunicação directa é mesmo o fundamento, a inteligibilidade, de todo o conhecimento (1) e de toda a acção moral (2) pois,

os modos de comunicação indireta pressupõem a experiência mais original da comunicação direta. É somente sobre o fundo desta experiência original da intersubjetividade humana, que Kant analisa na Crítica da Faculdade de Julgar Estética, que podem desenvolver-se as modalidades indiretas da comunicação. (ibidem, p. 11)

Assim, esta "Crítica da Faculdade de Julgar" adquire uma importância fundamental no sistema ao constituir-se numa "lógica da intersubjectividade", quer dizer, "(...) como uma lógica da significação"1. De acordo com Philonenko, “(...) a Estética (...) penetra neste lugar original onde dois seres que tudo separa por um olhar objectivo se unem e põem de acordo num juízo de gosto" (ibidem, p. 12).

Reforçando ainda mais a importância da "Crítica da Faculdade de Julgar" no contexto da obra de Kant, Philonenko chama a atenção para a existência de uma ligação vertical entre as três Críticas. Pode-se considerar a Filosofia kantiana como uma 'doutrina dos abismos do espírito', os quais seriam o abismo da existência objectiva (a incognoscibilidade do númeno), o abismo da organização (o mundo não é avulso mas constitui um reino dos fins) e o abismo da individualidade e da personalidade ou da vida que é tratado na CFJ no âmbito da qual se conclui que a organização não é por si só vida, pois falta-Ihe a individualidade, ou, noutros termos, a subjectivação (veja-se a diferença entre um homem e uma árvore). Só no homem surge a consciência que torna possível "saber de si como de um eu" (ibidem, p. 14). Estamos em pleno processo de subjectivação, totalmente imersos no domínio da criação e fruição artísitica.

E será ainda a partir deste 3) abismo que encontraremos um 4): o abismo da personalidade: qual é o destino do homem? (questão da "Razão Prática" à qual também a "Crítica da Faculdade de Julgar" nos conduz).
Assim, se na "Crítica da Razão Pura" tinham sido estabelecidos os princípios a priori do entendimento e a legitimidade do seu uso (logo, os seus limites), bem como a função reguladora das ideias; se na "Crítica da Razão Prática" foi estabelecido o único princípio a priori que aí se encontra e que se conecta à faculdade de desejar, trata-se agora de perguntar se a faculdade de julgar possui princípios a priori; se sim, são eles constitutivos ou simplesmente reguladores (não indicando assim um domínio próprio) e, finalmente, se a faculdade de julgar dita uma regra aos sentimentos do prazer e de pena, uma vez que se trata do meio termo entre a faculdade de conhecer e desejar.

\section{2 - Analítica do Belo}

Kant começa por definir a faculdade de julgar em geral como "(...) a faculdade que consiste em pensar o particular como compreendido sob (no) universal (...)" (KANT, 1974, p.27). Porém, o juízo de gosto é estético e não é um juízo de conhecimento. Por consequência, ele não é lógico, mas subjectivo: ele não designa nada no objecto, mas relacionase apenas com a maneira pela qual o sujeito sente quando é afectado pela representação. A satisfação que determina o juízo de gosto é desinteressada.

Para além disso, o juízo de gosto afirma a indepedência do sujeito face ao objecto:

Vemos facilmente que o Que é importante para dizer de um objeto que ele é belo e provar que eu tenho gosto, é o que eu descubra em mim com base nessa representação e não aquilo que em mim possa depender da existência de objeto. (...) Para servir como juiz em matéria de gosto a última coisa com que me devo preocupar é com a existência do objecto, mas pelo contrário ser indiferente a tudo a que a isso diga respeito. (ibidem, p.50)

Assim, a revolução copernicana que Kant traz também para a estética consiste no seguinte: a universalidade estética não diz respeito ao conceito do objecto, considerado na sua esfera lógica, mas à esfera dos sujeitos que ajuízam. Os juízos de gosto são singulares, embora possa deles resultar um juízo lógico universal. De forma a precisar o alcance desta universalidade, Kant acrescenta: "desde que produzamos um juízo sobre os objectos unicamente apoiados em conceitos, toda a representação de beleza desaparece. Não podemos pois indicar uma regra a partir da qual alguém poderia ser obrigado a reconhecer a beleza de uma coisa" (ibidem, p.59). 
E ainda:

Por onde se vê que, no juízo de gosto não é postulado nada mais do que essa universalidade das vozes em relação à satisfação sem a mediação dos conceitos; em consequência <postula-se> a possibilidade de um juízo estético Que pudesse ser considerado válido, ao mesmo tempo por todos. O juízo de gosto não postula ele próprio a adesão de cada um (só um juízo lógico universal pode fazê-lo, porque ele pode apresentar razões); ele não faz senão atribuir a cada um esta adesão como um caso da regra, da qual ele aguarda a confirmação do acordo dos outros, e não os conceitos. $O$ assentimento universal é, portanto, apenas uma ideia (...). (ibidem, p.59-60)

Ouseja, nojuízo degosto primeirovemaconsideração sobre o objecto e só depois o sentimento de prazer: de acordo com Kant, é a comunicabilidade universal do estado de espírito atingido no juízo de gosto que é o seu fundamento: "a universal comunicabilidade subjetiva do modo de representação num juízo de gosto, devendo produzir-se sem pressupor um conceito determinado, não pode ser qualquer outra coisa senão o estado de espírito no livre jogo da imaginação e do entendimento (desde que se ponham de acordo entre si, como é necessário para o conhecimento em geral)" (ibidem, p.61).

Assim, este estado de um jogo livre das faculdades de conhecimento numa representação (que deve poder comunicar-se universalmente) precede (e é a origem) do prazer que o objecto representado proporciona. Na verdade, "o que incita as duas faculdades (imaginação e entendimento) para uma atividade não-determinada, mas apesar disso comum em função da representação dada (;) é a sensação a partir da qual o juízo de gosto postula a comunicabilidade universal" (ibidem, p.62).

Assim, Kant apresenta outra dimensão do Belo: "é belo o que agrada universalmente sem conceito" (idem), à qual acrescenta ainda que não há nenhum fim (nem objectivo nem subjectivo) no objecto cuja representação suscita o juízo de gosto, mas este fundamenta-se na simples forma da finalidade subjectiva presente na representação.

Duas outras ideias são ainda acrescentadas por Kant à noção de Belo: "A beleza é a forma da finalidade de um objeto, desde que seja percebido nele próprio sem representação de um fim" (ibidem, p.76), e ainda "É belo o Que é reconhecido sem conceito como objecto de uma satisfação necessária" (ibidem, p.80).
Ambas sublinham a ausência de uma lei, fim ou conceito que pré-determine o objecto de arte, mas que os sujeitos podem intersubjectivamente reconhecer como tendo um fim em si próprio e comunicando o sentimento de satisfação que a ambos os atravessa a propósito daquele objecto.

Kant recorda aqui que o conceito de gosto consiste numa "(...) faculdade de julgar um objeto em relação à legalidade livre da imaginação" (ibidem, p.80) e que a imaginação é produtiva e espontânea, enquanto criadora de formas arbitrárias de intuições possíveis.

Trata-se, finalmente, de "(...) legalidade sem lei, e um acordo subjectivo da imaginação com o entendimento sem acordo objectivo, uma vez que neste último caso a representação está ligada a um conceito determinado do objecto(...)" (ibidem, p.81).

\section{3 - Analítica do Sublime}

Tanto o Belo como o Sublime têm em comum o facto de agradarem por eles mesmos, ou seja, suporem um juízo por reflexão e não um juízo determinante, nem algo proveniente meramente dos sentidos. Tanto num como noutro caso, trata-se de juízos singulares, que se dão a cada sujeito como universalmente válidos, embora sem qualquer pretensão no que respeita ao conhecimento dos objectos, mas apenas respeitando ao sentimento de prazer.

Há, no entanto diferenças consideráveis entre ambos:
(...) o belo parece adequar-se à apresentação de um conceito indeterminado do Entendimento, e o sublime a um conceito indeterminado da Razão. Assim a satisfação relativa ao belo está relacionada com a representação da qualidade, e no outro caso está relacionada com a quantidade. (KANT, 1974, p.84)

Deste modo, enquanto o belo conduz a um sentimento de 'épanouissement' (florescimento) da vida e é susceptível de ser ligado à atracção e à imaginação, no caso do sublime a fruição é indirecta e suscita antes a admiração e o respeito, pelo que se trata de um prazer negativo.

A apreciação lógica de uma dada grandeza é algo de objectivo, mas a sua apreciação estética é uma medida simplesmente subjectiva. A representação em nós de uma tal grandeza provoca normalmente uma satisfação, mesmo que o objecto seja desprovido de forma. Trata- 
se, segundo Kant, de uma satisfação relativa à extensão da imaginação, ela mesma.

Quando dizemos que uma coisa é absolutamente grande, e por isso sublime, o que pretendemos dizer é que nenhuma medida fora dessa coisa é apropriada para avaliar a sua grandeza².

Assim, para Kant, é Sublime aquilo que "revela" uma faculdade da alma que ultrapassa toda a medida dos sentidos. Ou, por outros termos, o que é Sublime é o nosso sentimento de infinitude face às possibilidades do mundo e da vida (e não um dado objecto ou realidade, concreta ou virtual), facto que abre portas à possibilidade de uma infinita subjectivação (que não a manipulação objectiva do mundo - impossível de realizar precisamente pela sua infinitude -, pois o que é admirável/sublime não é o mundo mas o sujeito). Trata-se também aqui de uma verdadeira revolução copernicana!

Com efeito, para Kant, toda a avaliação da grandeza dos objectos da natureza é, ao fim e ao cabo, estética (quer dizer, subjectivamente e não objectivamente determinada):

(...) para a avaliação estética da grandeza há um máximo e eu digo sobre isso que, uma vez considerada como uma medida absoluta, em relação à qual não há nada que possa ser subjetivamente maior (para o sujeito que ajuíza), isso implica a Ideia do sublime e produz essa emoção que nenhuma avaliação matemática da grandeza pelos números seria capaz de suscitar (...). (ibidem, p.91)

É a Razão que exige a presentação de um todo infinito, pretendendo que o infinito possa ser pensado como um todo (o que ultrapassa toda a medida dos sentidos). Ora, como pensar a grandeza infinita leva ao sentimento do Sublime, então "a natureza é tão mais Sublime nos seus fenómenos, quanto a intuição suscite a Ideia da sua infinitude" (ibidem, p.94).

Mas toda a avaliação estética da grandeza exige um esforço para chegar à sua compreensão, ao mesmo tempo que se reconhece a sua impotência, dado que o todo da natureza (o infinito) não pode ser dado nos sentidos. Assim, verdadeiramente não é o objecto que é sublime, mas a disposição da alma na avaliação do objecto: “(...) o verdadeiro sublime não está senão na mente de quem avalia e que de modo algum o devemos procurar no objecto natural, que suscita esta disposição no sujeito" (ibidem, p.95).
Em seguida Kant dá como exemplo de Sublime as massas montanhosas sem forma e o Sublime matemático, reiterando que o Sublime se encontra não nos objectos mas no sujeito.

O Sublime é ainda um sentimento de pena, suscitado pela insuficiência da imaginação na avaliação estética da grandeza para a avaliação da razão. É, ao mesmo tempo, um sentimento de alegria porque tudo que a natureza apresenta como objecto aos nossos sentidos é demasiado pequeno em comparação com as Ideias da Razão, acordando em nós o sentimento da nossa destinação supra-sensível. Ou pelo menos da nossa subjectivação infinita.

Assim, enquanto ao nível do belo a finalidade subjectiva encontrava-se por um jogo harmonioso entre o entendimento e a imaginação, ao nível do sublime essa mesma finalidade é produzida pelo conflito entre imaginação e Razão.

Em conclusão:

(...) o sublime não está contido em nenhuma coisa da natureza, mas apenas no nosso espírito, na medida em que podemos nos tornar conscientes de sermos superiores à natureza em nós (apesar de ela exercer a sua acção em nós). Tudo o que em nós suscita esse sentimento, como a força da natureza, que solicita as nossas forças, é portanto dito Sublime (mas incorrectamente); e é apenas sob a pressuposição dessa Ideia em nós e em relação a esta que nós somos capazes de chegar à Ideia da natureza sublime deste Ser, que faz nascer um profundo respeito não só pela força, que se manifesta na natureza, mas ainda e sobretudo pela faculdade, que está em nós, para julgar isto sem medo e pensar que o nosso destino é ainda mais sublime. (ibidem, p.102)

Deste modo, o juízo estético sobre o Sublime não supõe necessariamente erudição, mas disposição para o sentimento pelas Ideias (práticas), ou seja, para o sentimento moral. A cultura introduz apenas algo de convencional na sociedade e o sublime, pelo contrário, enraíza-se na natureza humana e é aí que se funda "(...) a necessidade do acordo do juízo do outro sobre o sublime com o nosso, e nós compreendemo-lo ao mesmo tempo no nosso" (ibidem, p.103).

Kant dá ainda outros dois exemplos de sublime: o céu estrelado (um véu vasto que compreende tudo) e o oceano, visto como os poetas o veem: “(...) segundo o espectáculo que ele dá à vista, seja quando é contemplado em repouso como um espelho de água claro que não está limitado senão pelo céu e, logo que agitado, seja como um abismo 
ameaçando tudo engolir, sendo-nos de qualquer modo possível encontrar o sublime" (ibidem, p.107).

Quanto à forma humana, o Sublime também não se encontra procurando racionalmente a lógica dos seus membros ou das suas formas (isso fica para a ciência) mas, recorda Kant,

a finalidade estética consiste na legalidade da faculdade de julgar na sua liberdade. A satisfação que resulta do objecto depende da relação na qual nós queremos colocar a nossa imaginação; é necessário somente que dela própria ela mantenha o espírito numa actividade livre. Pelo contrário, se uma outra qualquer coisa determina o juízo, quer se trate de uma sensação ou de um conceito do entendimento, pode haver aí uma certa legalidade, mas não há mais o juízo de uma faculdade livre de julgar. (idem)

\section{Um passo atrás em direcção ao homem ou ao ciborg-homem}

Após esta longa viagem através da estética de Kant, para a qual Santaella/Pierce serviu de estímulo e Luc Ferry de guia, nalgumas das principais intuições desta reflexão, queremos concluir afirmando que o que é Admirável não é o mundo e as suas possibilidades técnicas de subjectivação virtual e infinita através de uma expansão técnica e maquínica que faria dele em última análise um criador-Deus, num sistema monodológico, hipernarcísico e, em última análise, de incomunicação.

Em vez disso, propomos, recuando um passo atrás até Kant, substituir o conceito de Admirável pelo de Sublime, pois Sublime é o Homem (seja lá o que isso for; poderemos mesmo adoptar o conceito híbrido de ciborg-homem) e são as suas possibilidades de intersubjectivação, infinitas por natureza, horizontes abertos pela possibilidade de uma comunicação que não está garantida por nenhuma lei a priori ou divina, mas que ainda assim retira do particular (do objecto artístico concreto ou tão somente da arte em geral) a possibilidade de uma comunicação empática universal entre todos os homens, com os seus mundos reais, virtuais, maquínicos e corporais.

E não é de outra coisa que nos fala o "Manifesto Cyborg" de Donna Haraway quando nos remete para as 'vertigens do pós-humano' (cf. HARAWAY; KUNZRU; TADEU, 2000) em Antropologia do Cyborg. Na verdade, o Cyborg não funda uma outra antropologia que não seja a do Humano. De facto ela revela outro e meso humano, que poderemos chamar de pós-humano, cyborg, corpo-maquínico, super-homem, ciborg-homem, mas ainda assim estamos face a um discurso sobre o infinitamente humano, dessubstantivado, desessencializado agora, mas não dessubjectivado.

Ou, como refere Tomaz Tadeu, "o ciborgue nos força a pensar não em termos de "sujeitos", de mônadas, de átomos ou indivíduos, mas em termos de fluxos e intensidades, tal como sugerido, aliás, por uma "ontologia" deleuziana. O mundo não seria constituído, então, de unidades ("sujeitos"), de onde partiriam as ações sobre outras unidades, mas, inversamente, de correntes e circuitos que encontram aquelas unidades em sua passagem. Primários são os fluxos e as intensidades, relativamente aos quais os indivíduos e os sujeitos são secundários, subsidiários" (ibidem, p.15) É então de possibilidades infinitas de comunicabilidade, (inter)subjectivação infinita, hibridação, trocas, mistura e implosão de limites que estamos a falar em primeiro lugar, numa linha que nesta reflexão quisemos fazer remontar à "Crítica da Faculdade de Julgar" de Kant.

Tudo o resto participa, como muito bem o coloca Haraway logo no início do seu "Manifesto Cyborg" de

\begin{abstract}
um mito político, pleno de ironia, (...) fiel ao feminismo, ao socialismo e ao materialismo. Um mito que poderá ser, talvez, mais fiel - na medida em que a blasfémia possa sê-lo - do que uma adoração ou uma identificação reverente. A blasfémia sempre exigiu levar as coisas a sério. (;) A blasfémia nos protege da maioria moral interna, ao mesmo tempo em que insiste na necessidade da comunidade. Blasfémia não é apostasia. A ironia tem a ver com contradições que não se resolvem - ainda que dialeticamente - em totalidades mais amplas: ela tem a ver com a tensão de manter juntas coisas incompatíveis porque todas são necessárias e verdadeiras. A ironia tem a ver com o humor e o jogo sério. Ela constitui também uma estratégia retórica e um método político que eu gostaria de ver mais respeitados no feminismo socialista. No centro de minha fé irónica, de minha blasfémia, está a imagem do ciborgue. (ibidem, p.35)
\end{abstract}

Levemos Haraway a sério: o ciborg é um mito; o ciborg é uma estratégia retórica; o ciborg é uma política dos corpos e da possibilidade da intersubjectivação comunicativa. O ciborg não é uma coisa, mas uma estratégia de resistência construtiva em comunidade, quer dizer em intersubjectividade e intersubjectivação. O ciborg estende os limites do humano no humano. Ele é " $(;)$ um argumento em favor do prazer da confusão de fronteiras, bem como em favor da responsabilidade 
em sua construção" (ibidem, p.37).

Deste modo, o "admirável" pós-homem de Santaella/Pierce, deus criador e todo poderoso de uma realidade que pode ser infinitamente expansível, deverá ser em nosso entender substituído, num passo atrás, pela imagem irónica e blasfema do ciborg-homem que, no embate com o mundo, as ideias, a natureza, os animais as máquinas, os mundos virtuais e os reais, encontra a revelação da dimensão Sublime da sua própria existência, inscrita nos seus próprios processos de subjectivação e comunicabilidade de que só a arte (toda a arte) dá pleno e admirável testemunho.

\section{REFERÊNCIAS}

CASSIRER, E. Filosofia das Formas Simbólicas. México: Fondo de Cultura Económica, 1998.

FERRY, Luc. Homo Aestheticus - L'invention du goût à l'âge démocratique. 2eme edition. Paris: Bernard Grasset, 1991. (Collection Le Collège de Philosophie).

HARAWAY, Donna; KUNZRU, Hari; TADEU, Tomaz (Orgs.). Antropologia do Ciborgue - As Vertigens do Pós-humano. 2. ed. Belo Horizonte: Autêntica, 2000.

HEGEL, G. W. F. La Phénoménologie de L'Esprit, Tome II. Traduction Jean Hyppolite. Paris: Aubier, Éditions Montaigne, [s.d].

HEGEL, G. W. F. Estética. Lisboa: Guimarães Editores, 1993.

KANT, Emmanuel. Critique de la Faculté de Juger. 3ème edition. Traduction par A. Philonenko. Paris: Librairie Philosophique J. Vrin, 1974.

LEIBNIZ, G. W. La Monadologie. Paris: Librairie Delagrave, 1925.

PHILONENKO, A. Introduction. In: KANT, Emmanuel. Critique de la Faculté de Juger. 3ème edition. Paris: Librairie Philosophique J. Vrin, 1974. p. 7-21.

PIERCE, C. S. Escritos Coligidos. Tradução Armando D'Oliveira e Sérgio Pomerangblum. In: Os Pensadores. São Paulo: Abril Cultural, 1974. v. 36 .

SAntaella lúcia. Culturas e Artes do PósHumano - da cultura das mídias à cibercultura. 3.ed. São Paulo: Paulus, 2008.

VATTIMO, Gianni. 0 fim da modernidade. Niilismo e Hermenêutica na cultura pós-moderna. São Paulo: Martins Fontes, 1985.

VATTIMO, G.; RAVOTTI, Pier Aldo. EI Pensamiento Débil. Madrid: Cátedra, 1990.

\section{Sobre a autora}

Maria Manuel Rocha Teixeira Baptista é Professora Auxiliar com Agregação da Universidade de Aveiro, Portugal e Diretora, na Universidade de Aveiro, do Programa Doutoral em Estudos Culturais das Universidades de Aveiroe do Minho. Em2013, realizou as suas Provas de Agregação na Universidade do Minho, na área de especialização de Hermenêuticas Culturais. Doutorou-se em Cultura pela Universidade de Aveiro, em 2002, com especialização em Filosofia da Cultura. Concluiu, em 1996, o Mestrado em Psicologia da Educação pela Faculdade de Psicologia e Ciências da Educação da Universidade de Coimbra e licenciou-se em Filosofia pela Faculdade de Letras da Universidade do Porto, em 1986. No mesmo ano de 1986 começou a sua atividade profissional como jornalista e desde então lecionou e conduziu investigação em Estudos Culturais, nas áreas de intersecção entre as Ciências Humanas e Sociais. Nos últimos anos seus interesses de investigação estão centrados principalmente nos estudos póscoloniais, de género, e do ócio e do turismo cultural, áreas em que também tem orientado diversos doutoramentos, pós-doutoramentos e mestrados. Nos últimos anos tem-se interessado também pelas relações entre a universidade e o ativismo social. Participa de diversas redes de investigação nacionais e internacionais. É coeditora da Revista Lusófona de Estudos Culturais UA/UM (http://estudosculturais. com/revistalusofona/index.php/rlec/index) e membro do Conselho Científico desta e de muitas outras publicações científicas. Tem obra diversa publicada nacional e internacionalmente na área dos Estudos Culturais (consultar página web: http:// mariamanuelbaptista.com/publicacoes.htm). 